\title{
A rare case report of large bilateral vulval elephantiasis
}

\author{
Manmeet Kaur ${ }^{1}$, Renuka Malik ${ }^{1 *}$, Kamna Dutta ${ }^{1}$, Kaveri Khera ${ }^{2}$
}

\author{
${ }^{1}$ Department of Obstetrics and Gynecology, ABVIMS and Dr. RML Hospital, New Delhi, India \\ ${ }^{2}$ Department of Microbiology, ESI Hospital, Noida, Uttar Pradesh, India
}

Received: 06 April 2020

Accepted: 29 April 2020

\section{*Correspondence:}

Dr. Renuka Malik,

E-mail: renucam@yahoo.co.in

Copyright: (C) the author(s), publisher and licensee Medip Academy. This is an open-access article distributed under the terms of the Creative Commons Attribution Non-Commercial License, which permits unrestricted non-commercial use, distribution, and reproduction in any medium, provided the original work is properly cited.

\begin{abstract}
Elephantiasis, the result of chronic lymphedema, is characterized by gross enlargement of the limbs or genitalia. It occurs because of obstructive diseases of the lymphatic system. Genital elephantiasis is a common result of filariasis. Other causes are lymphogranuloma venereum. granuloma inguinale, carcinomas, lymph node dissection, irradiation and tuberculosis. Filarial elephantiasis of the female genitalia is extremely uncommon, about $1-2 \%$ of the total cases of filarial elephantiasis. Mrs. X, 25 years old female, P1L1, resident of a village in Bihar presented to gynaecology OPD of ABVIMS and Dr. RML Hospital on $06^{\text {th }}$ January 2020 with complaint of huge progressively increasing vulval swelling since 3 years. Patient had come from Bihar for treatment. She had been showing in her native place for 2 years but now the lump had made her walking difficult. She did not give history of any drug given for treatment for filariasis. She gave history of being treated for pulmonary Koch 10 years back. On examination, there was a nonulcerative, polypoidal growth of around $20 \times 14 \times 11 \mathrm{~cm}$ arising from bilateral labia majora and minora obstructing the vulval cleft. There was no associated lymphadenopathy or limb oedema. All the investigations were within normal limits. Microfilaria antigen testing done at night was negative. Patient was given diethylcarbamazine and excision of the lump was done on $14^{\text {th }}$ February 2020. Histopathological report showed dilated lymphatics with non-caseating granulomas, consistent with filariasis. In endemic countries like India, filariasis is the commonest cause of elephantiasis; however genital filariasis in woman is very rare. Other cause could be tuberculosis which is still rarer. Early diagnosis and treatment of filariasis can eradicate this neglected tropical disease which causes disfigurement and severe morbidity as its sequelae.
\end{abstract}

Keywords: Filariasis, Vulval elephantiasis, Vulval lymphedema

\section{INTRODUCTION}

Vulval elephantiasis is lymphedema of soft tissues that develops following accumulation of protein rich interstitial fluid secondary to improper lymphatic drainage of the involved area. It is caused by infections like filariasis, tuberculosis, lymphogranuloma venereum, donovanosis and non-infective conditions like genital malignancies, metastatic crohn's disease, inguinal and pelvic lymph node dissection, genital radiation and trauma. ${ }^{1}$ In endemic countries lymphatic filariasis is the commonest cause of lymphedema which mostly affects the lower limbs, arms and rarely genital organs. Filarial elephantiasis of vulva in females accounts for only $1-2 \%$ of total lymphedema cases. ${ }^{2}$ Lymphatic filariasis is a vector borne disease of tropical and subtropical countries, often called as neglected tropical disease, due to infection by filarial nematodes which invade the lymphatics of human body, initiating pathological changes, leading to later disease manifestations. Nematode species that cause lymphatic filariasis include mostly wuchereria bancrofti $(90 \%)$, to a lesser extent brugia malayi (10\%) and rarely with brugia timori. ${ }^{3}$

\section{CASE REPORT}

Mrs. X, 25 years old female, P1L1, resident of Hatwariya village in Bihar presented to gynaecology OPD of 
ABVIMS and Dr. RML Hospital on $06^{\text {th }}$ January 2020 with complaint of a huge swelling over the vulval region since 3 years which was initially involving the right labia majora and gradually increased in size to present state involving whole vulval region. Patient was uneducated and belonged to poor socioeconomic status. There was no history of fever or pain associated with swelling. There was no history of having taken any treatment for filariasis. Patient had history of pulmonary tuberculosis in childhood for which ATT for 6 months was taken. On general physical examination, patient was afebrile and there was no lymphadenopathy or any scars and sinuses. There was no evidence of leg oedema. Local examination revealed a growth measuring $20 \times 14 \times 11 \mathrm{~cm}$ involving both labia majora and minora obstructing the vulval cleft (Figure 1).

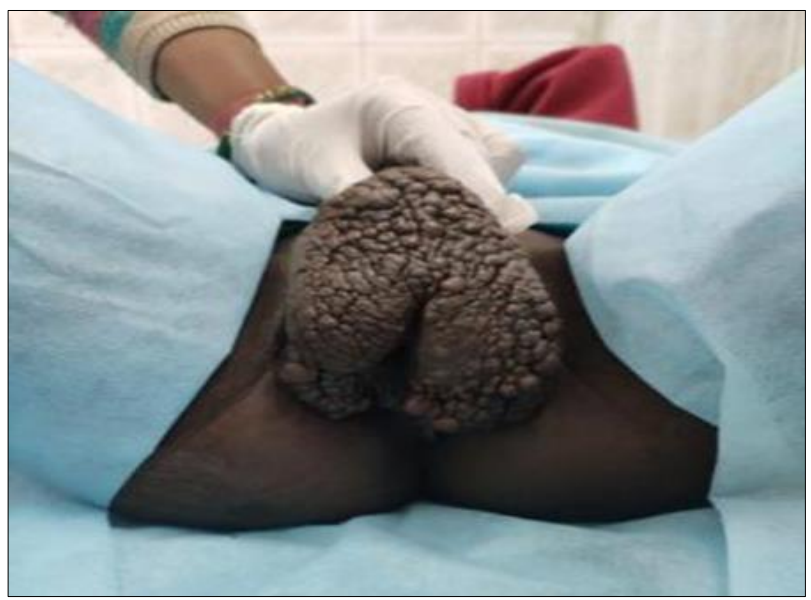

Figure 1: Vulval elephantiasis.

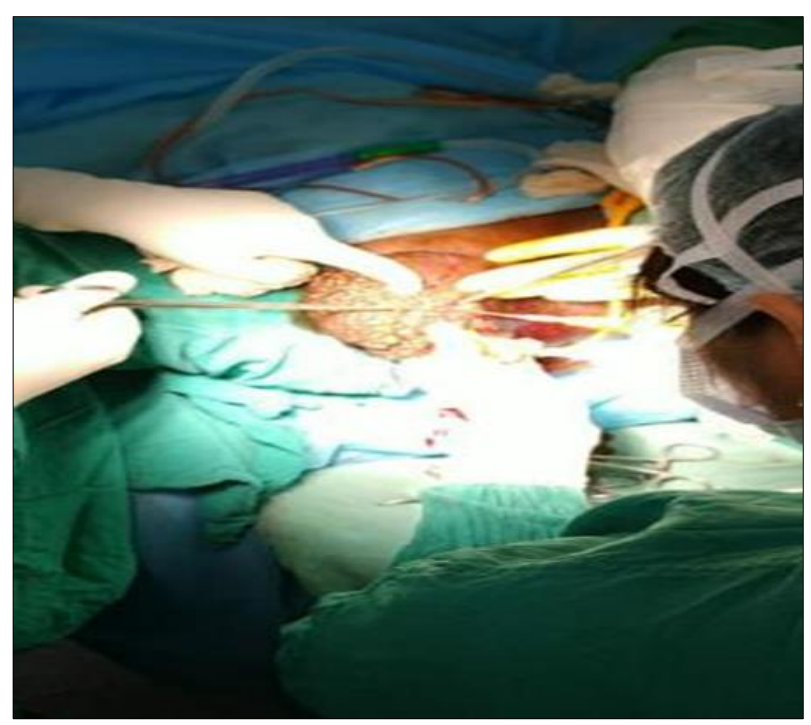

Figure 2: Excision of vulval lump.

It was non tender and non-ulcerative with bosselated surface showing hyper-keratosis with wart-like protuberances, hard in consistency. A provisional diagnosis of vulval elephantiasis secondary to filariasis or tuberculosis was made. All the routine investigations sent were normal. No eosinophilia was found. Chest X-ray was normal. A night blood sample was negative for microfilaria antigen of wuchereria bancrofti. A repeat carbamazine provocation test done during day too was negative for microfilaria. Following dermatology reference, diethylcarbamazine in the dose of $6 \mathrm{mg} / \mathrm{kg} / \mathrm{day}$ in three divided doses was given for 21 days. Excision of the lump and vulval reconstruction was done under regional anaesthesia on $14^{\text {th }}$ February 2020 (Figure 2, 3, 4).

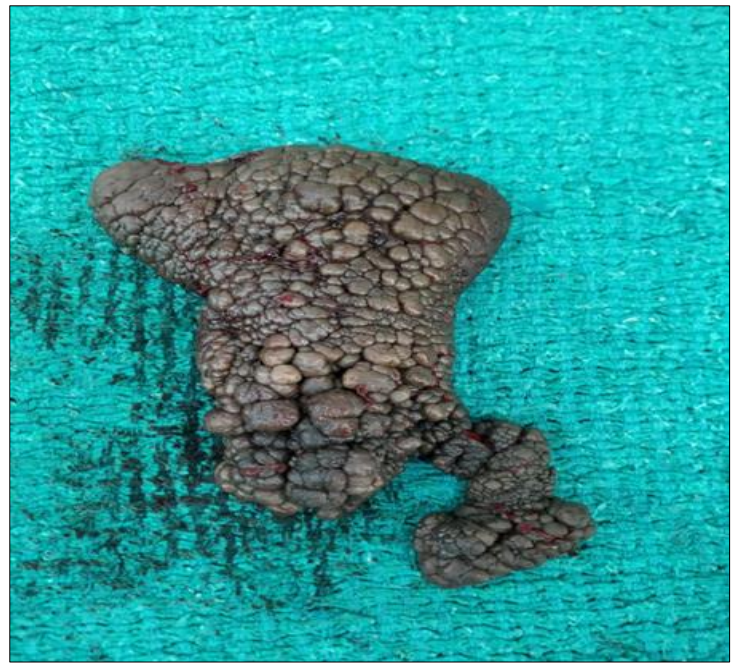

Figure 3: Excised vulval lump.

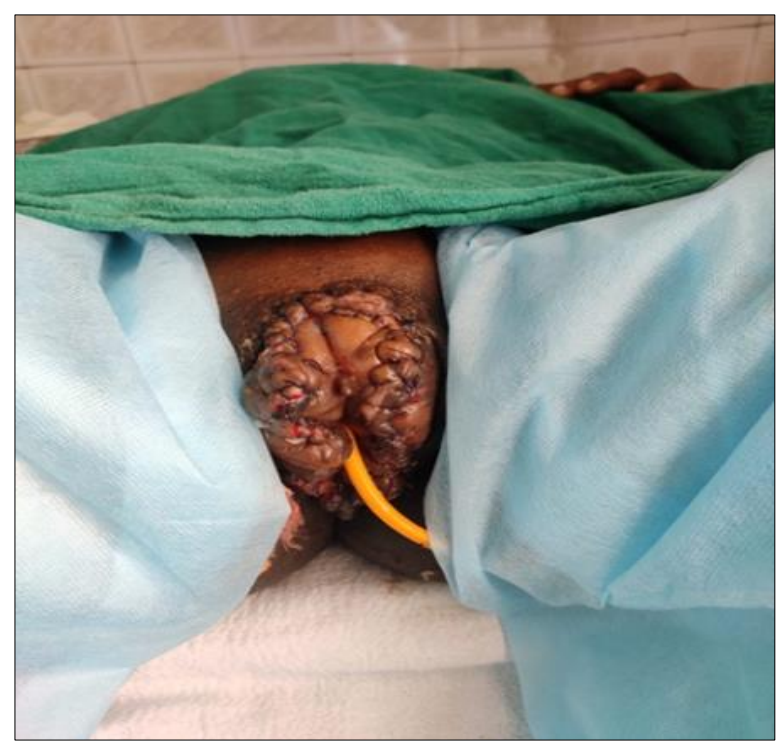

Figure 4: Reconstructed vulva.

Mass excised was sent for histopathological examination. Postoperative period was uneventful. Patient was discharged on postoperative day 10 in satisfactory condition. The histopathological report showed hyperkeratosis and acanthosis with sub-epithelium showing many dilated lymphatics surrounded by illdefined collection of histiocytes, epitheloid cell non- 
caseating granuloma along with peri lymphatic fibrosis (Figure 5,6). AFB and fungal staining were negative.

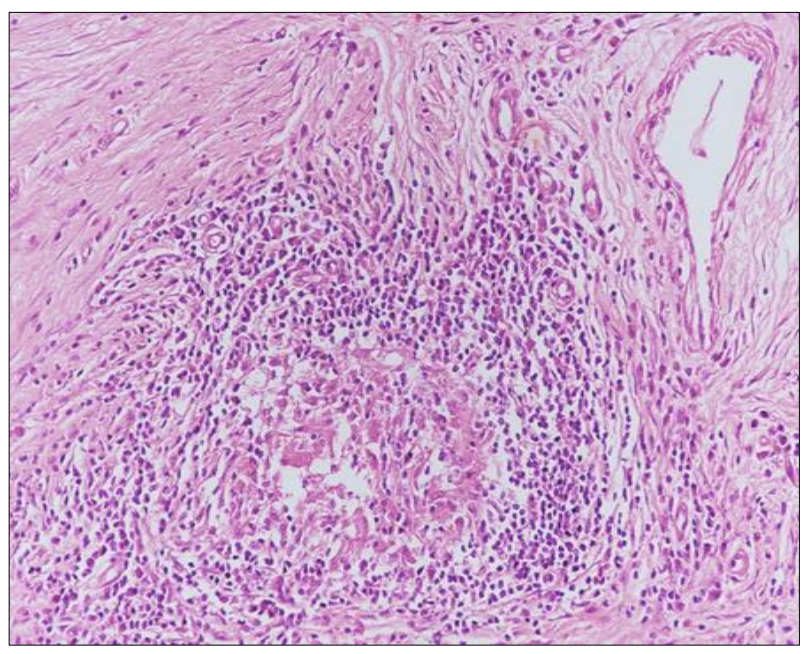

Figure 5: Perilymphatic epithelioid cell non-caseating granuloma.

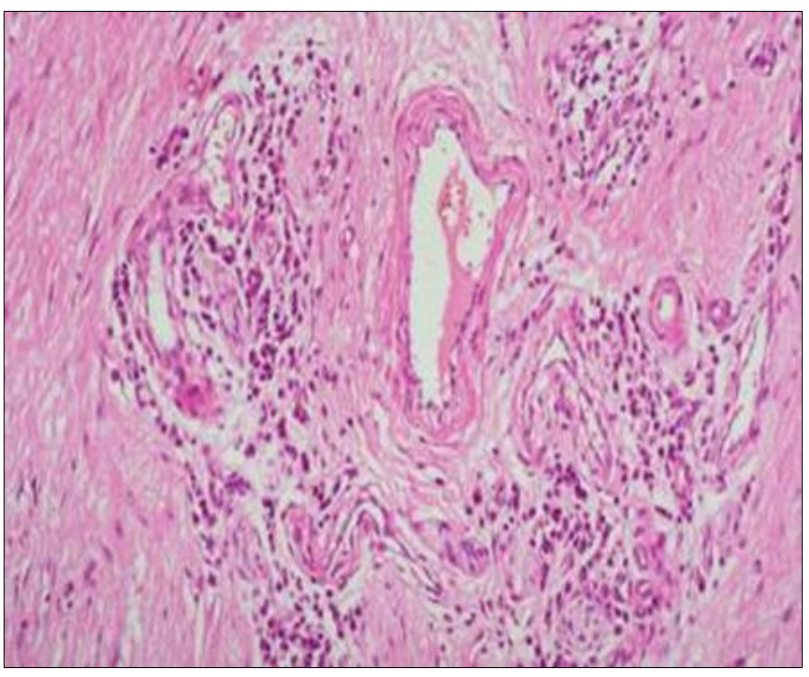

Figure 6: Dilated lymphatics with perilymphatic fibrosis and dense lymphoplasmacytic infiltrate.

\section{DISCUSSION}

Genital elephantiasis due to filariasis is very rare accounting for only $1-2 \%$ of filarial cases., ${ }^{3,4}$ Vulval filarial elephantiasis is a potentially disabling and disfiguring disease caused by vector borne nematodes wuchereria bancrofti, brugia malayi and brugia timori. Infection is generally acquired early in childhood; the disease may take several years to manifest. Acute manifestations of the disease include acute adenolymphangitis (ADL), acute dermatolymphangioadenitis (DLA), filarial fever and tropical pulmonary eosinophilia. The chronic and most debilitating sequelae of filariasis often develop years after initial infection. In Bancroftian filariasis, the main clinical features are hydrocoele, lymphedema, elephantiasis and chyluria whereas for brugian filariasis the urogenital areas are commonly spared. Lymphedema is a chronic manifestation. Advanced stages of lymphedema are characterized by increasing dilation and tortuosity of the lymphatics, endothelial proliferation, formation of new lymph channels, and obstructive changes with dermatosclerosis including nodular and warty changes as seen in this case. The most severe symptoms of chronic disease generally more common in males than females. ${ }^{4,5}$

At present, three laboratory methods are used for diagnosing active infections with wuchereria bancrofti, namely demonstration of microfilaria in night blood specimens, detection of circulating filarial antigens (CFA) and detection of filarial DNA in human blood by polymerase chain reaction (PCR). Antigen testing is most widely used for diagnosis. ${ }^{6}$ Immunology and ultrasonography to locate the adult worms are usually negative once lymphedema is established as was seen in this case.

The case patient was a resident of a village in Bihar. In India, Bihar state has highest endemicity for filariasis (over 17\%) followed by Kerala (15\%) and Uttar Pradesh $(14 \%) .{ }^{7}$ In India, wuchereria bancrofti transmitted by the ubiquitous vector, culex quinque fasciatus, has been the most predominant infection contributing to $99.4 \%$ of the problem in the country. The infection is prevalent in both urban and rural areas. Circulating filarial antigen (CFA) detection test is the 'gold standard' for diagnosing wuchereria bancrofti infections. ${ }^{8-10}$ It is very sensitive in acute cases but may be negative in chronic cases like ours. The patient presented with grade 3 lymphedema which is the stage of elephantiasis. The histopathological features in this case were suggestive of filariasis. Identification of an adult worm in tissue sections is difficult on histopathology as death of the worm causes progressive fibrosis, obliteration of vessels by granuloma and extensive perilymphatic inflammation. Tuberculosis can also cause Elephantiasis as seen by Chintamani et al. ${ }^{11}$ In this case tuberculosis was another possibility but negative AFB staining and non-caseating granulomas supported filariasis as a cause of elephantiasis.

Elephantiasis is a preventable morbidity. The Global Program to Eliminate Lymphatic Filariasis (GPELF) coordinated by the World Health Organization (WHO) aims to eliminate lymphatic filariasis (LF) by 2020 using repeated rounds of mass drug administration (MDA) 12 In filariasis control programme (1955) which has now been integrated as "elimination of lymphatic filariasis (ELF) programme' under the National Vector Borne Diseases Control Programme (NVBDCP), mass prophylaxis for filariasis is given annually in the form of diethylcarbamazine (DEC). Annually a single dose of one drug (ivermectin or DEC) administered can result in $90 \%$ reduction and single-dose co-administration of two drugs [ivermectin (I) + DEC or albendazole (A)] reduces blood microfilaria by $99 \%$ for a full year. ${ }^{10,12}$ Hydrocoele and 
genital elephantiasis have to be managed surgically. Filariasis has remained a public health problem in India despite the existence of National Filaria Control Programme since 1955 . It is prevalent in 17 states and 6 union territories. Compliance of the MDA has been the major challenge. India has missed 4 deadlines for eliminating LF- first in 2015, 2017, 2018 and now 2020. It has now been postponed to $2021 .^{12,13}$ The government launched the accelerated plan for elimination of lymphatic filariasis (APELF) in 2018, and as part of intensifying efforts towards elimination later rolled out IDA treatment (triple drug therapy) in a phased manner in 4 districts. ${ }^{13}$ Case patient had no knowledge or assistance belonging to a remote village. Patient awareness and compliance combined with the government efforts can make India filariasis free.

\section{CONCLUSION}

Vulval elephantiasis is a rare manifestation of filariasis which is endemic in our country. Mass prophylaxis under filariasis control programme can reduce its endemicity and sequelae.

Funding: No funding sources Conflict of interest: None declared

Ethical approval: Not required

\section{REFERENCES}

1. Joshi PL. Epidemiology of Lymphatic Filariasis. In Lymphatic Filariasis. Springer, Singapore; 2018:114.

2. Mohan H, Bisht B, Goel P, Garg G. Vulval elephantiasis: a case report. Case Rep Infect Dis. 2012;2012.

3. Chakraborty M, Banu H, Chakraborty PP. Bilateral vulval filarial elephantiasis. Case Rep. 2018:2018.

4. Palanisamy AP, Kanakaram KK, Vadivel S, Kothandapany S. Vulval elephantiasis. Indian Dermatol Online J. 2015;6(5):371.
5. Nutman TB. Insights into the pathogenesis of disease in human lymphatic filariasis. Lymph Res Biol. 2013;11(3):144-8.

6. Chesnais CB, Vlaminck J, Kunyu-Shako B, Pion SD, Awaca-Uvon NP, Weil GJ, et al. Measurement of circulating filarial antigen levels in human blood with a point-of-care test strip and a portable spectrodensitometer. Am J Trop Med Hyg. 2016;94(6):1324-9.

7. CDC - Lymphatic Filariasis, 2020. Available at: Cdc.gov. Accessed on $5^{\text {th }}$ April 2020.

8. Lu S, Tran TA, Jones DM, Meyer DR, Ross JS, Fisher HA, Carlson JA. Localized lymphedema (elephantiasis): a case series and review of the literature. J Cutaneous Pathol. 2009;36(1):1-20.

9. Nuchprayoon S. DNA-based diagnosis of lymphatic filariasis. Southeast Asian J Trop Med Pub Health. 2009;40(5):904.

10. Agrawal VK, Sashindran VK. Lymphatic filariasis in India: problems, challenges and new initiatives. Med J Armed Forces India. 2006;62(4):359-62.

11. Singh JP, Tandon M, Khandelwal R, Aeron T, Jain $\mathrm{S}$, Narayan N, et al. Vulval elephantiasis as a result of tubercular lymphadenitis: two case reports and a review of the literature. J Med Case Rep. 2010;4(1):369.

12. Ichimori K, King JD, Engels D, Yajima A, Mikhailov A, Lammie P, et al. Global programme to eliminate lymphatic filariasis: the processes underlying programme success. PLoS Neglected Trop Dis. 2014;8(12):e3328

13. Press Releases: Lymphatic Filariasis Elimination Program, 2020. Available at: Cartercenter.org. Accessed on $5^{\text {th }}$ April 2020.

Cite this article as: Kaur M, Malik R, Dutta K, Khera K. A rare case report of large bilateral vulval elephantiasis. Int J Reprod Contracept Obstet Gynecol 2020;9:2642-5. 